\title{
The Relevance of Subjective Benefits in Risky Choice Across ten Domains of Life
}

\author{
Jana B. Jarecki (jana.jarecki@unibas.ch,jj@janajarecki.com) \\ Center for Economic Psychology, University of Basel, Missionsstrasse 62a, \\ 4055 Basel, Switzerland \\ Andreas Wilke (awilke@clarkson.edu) \\ Evolutionary Behavioral Sciences, Clarkson University, Box 5825, 8 Clarkson Avenue, \\ Potsdam, NY 13699 USA
}

\begin{abstract}
In risk-research, there are two traditions of measurement: the attribute-based and the vignette-based tradition. The attributebased approach focuses on the impact that the attributes (probabilities and outcomes) of risky options have on the processing of risk-related information. The vignette-based approach focuses on responses to questions about contextualized situations involving risk. We bring these two approaches together here to investigate the stability of risk preferences and information processing in risky choice tasks across different contextualized situations. To this end, we employ an evidence-based multiattribute gamified risky choice task in a retest design. The results $(N=226)$ show that risk propensities are very stable within domains across time. Participants' explicit beliefs about risks and returns did not accurately reflect the actual rank order of the costs and benefits of actions in the real world, which we obtained from statistical databases. Also, we find that that prospect theory's risk-attitude parameters are mostly unrelated to the risk-taking in the contextualized task, and that benefit perceptions influence risk-taking, in line with a risk-return tradeoff view on risk-taking.
\end{abstract}

Keywords: domain-specific behavior; risky choice; risk preferences; prospect theory; cognitive modeling

\section{Introduction}

How general are human risk preferences? Previous work has started a debate about the temporal stability and the domain-generality of risk preferences and the validity of standard psychological measures of risk (Frey et al., 2017; Johnson et al., 2004; Nicholson et al., 2005). Risk preference, here, refers to people's attitudes towards and choices of actions with higher variability in outcomes compared to low-variability options.

One view on risk-taking is the risk-return framework. It holds that people's perceptions of the costs and benefits of the actions in question govern risk preferences (Weber, 1999; Weber \& Milliman, 1997), and this hypothesis has received some support (e.g., Nosić \& Weber, 2010). In different domains of risk, higher perceived benefits increase risk preferences, and perceived costs or risk decrease risk preferences (Blais \& Weber, 2006; Weber \& Milliman, 1997). The research in this field commonly uses questionnaire-based risk assessments. By contrast, cognitive psychology approaches risky decision making with a much stronger focus on varying the precise numeric attributes of the risky situation - testing how people process outcome magnitudes and probabilitiesto uncover mental information integtation (prominently, prospect theory; Kahneman \& Tversky, 1979; Tversky \& Kahneman, 1992). In this context, many studies, employ abstract tasks, either void of any meaningful context or from the financial domain, because in such tasks, prior beliefs should not influence risk processing (but see Pleskac \& Hertwig, 2014). To date, however, little is known about the integration of costs, benefits, and probabilities within contextualized domains of risk. We set out to combine the study of the effect of cost and benefit perceptions within risky choice domains with the impact of situational factors such as benefits and costs.

To do so, we designed an experiment based on the results of recent work (Jarecki \& Wilke, 2018) that explored the situational attributes that people recall when considering to engage in risky behaviors in ten different domains of life. The life domains that were studied in this work involved betweengroup competition, within-group competition, status and power, environmental exploration, food selection, food acquisition, parental investment, kinship, mate attraction, and mate retention (see also Table 1 below). The findings from this work resulted in the attributes of risky situations in ten different life domains that participants considered important for their choices. The experimental approach in the previous work, however, was limited because the experimental procedure asked people to recall the attributes of risky situations, rather than manipulating the characteristics of risky situations. Therefore, the precise effect of situation-specific risk attributes on risk propensities and their processing remains unclear. Further, it is not clear if the attributes contribute to risk preferences across domains, or if risk preferences are driven by the domain-specific perception of the costs and benefits associated with risky behaviors, in line with the riskreturn framework.

We aim to close this gap. We use the subjectively relevant attributes obtained in the previous study to devise a multi- 
attribute risky choice task in the ten life domains, which enables us to study the situational influences and cognitive processes more systematically. Further, we combine the new risky choice task with a traditional lottery-based risky choice task, which allows estimate individual-level risk aversion parameters from cumulative prospect theory to test to what degree prospect theory relates to risk-taking behavior in contextualized choice tasks.

\section{Materials and Methods}

The purpose of our experiment was to investigate the temporal stability, ecological validity, and cognitive processes in domain-specific risk-taking.

Participants. We invited participants for a two-part online choice study. A total of 287 people, recruited from introductory psychology students at a University in the United States, completed the first part; 61 (21\%) failed to complete the second session, resulting in $N=226$ complete responses (zero were excluded), 132 males and 94 females (58\% and $42 \%$, respectively), mean age 19 years $(\mathrm{Med}=19, S D=2$, range 17-38 years). Participants received course credits; data were collected from February to December 2019, the institutional review board at Clarkson University approved the study (\#19-21). The mean time interval between the first and the retest session was 9 days ( $M e d=8, S D=5$, range 5-70 days); the median study duration in the first part was 62 minutes $(M$ $=408, S D=1,474$, range 17-13,919 minutes). In our analyses, we did not exclude participants but report robustness checks (see "Robustness against the exclusion of participants" in the results section).

In terms of the demographics of the sample, the predominant native language was English ( $n=215,95 \%)$; the majority had an available monthly income after tax of up to 1,000 U.S. dollars ( $n=154,68 \%, n=15$ opted to not report income); most participants were not in a committed romantic relationship ( $74 \%$, one did not report it).

Design and Task. The study was a retest study with approximately one week between two sessions. The main task consisted in a multiple-attribute choice task about vignettes with uncertain consequences in ten different domains (see Table 1; Figure 1 shows one choice trials and one possible attribute combination). In the first session and before the choice task, participants were familiarized with the ten behaviors and it was made clear that each behavior might have both costs and benefits. Participants then reported the subjective size of the costs and benefits of engaging in all the behaviors ${ }^{1}$, beliefs about the probabilities of these benefits and $\operatorname{costs}^{2}$, filled in a domain-specific risk attitude scale (ERS, Wilke et al., 2014), and reported demographic and life-history data (not reported here). In the choice task, which was presented as "game of daily life", participants decided about engaging in or refraining from behaviors in ten domains, such as work weekends to

\footnotetext{
${ }^{1}$ Likert-type scale from $1=$ extremely small to $100=$ extremely large.
}

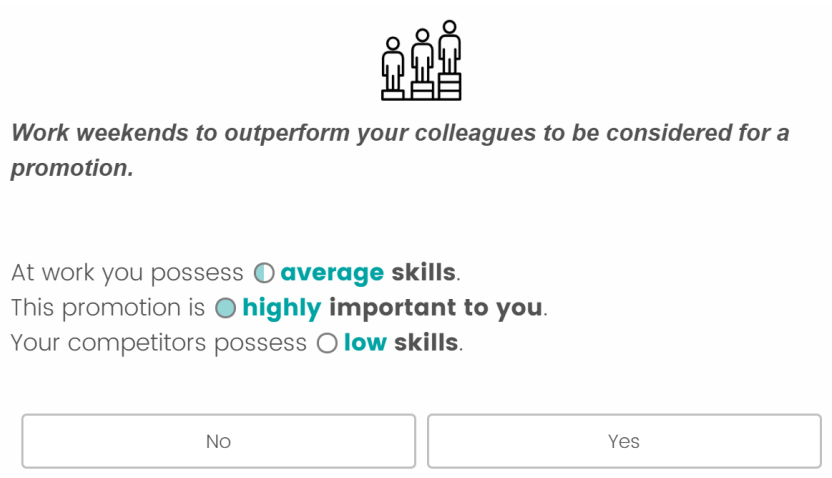

Figure 1. A sample trial of the multi-attribute choice task. Shown is a choice in the within-group competition domain; beneath the behavior are three attribute values showing the attribute values skill self $_{\text {f }}$ $=2$, importance $=3$, skill other $=1$.

outperform your colleagues to be considered for a promotion (within-group competition domain). Each behavior was characterized by three attributes with three possible values, such as for the within-group competition domain example: this promotion is not very [moderately, very] important to you; at work you possess low [average, high] skills; your competitors possess low [average, high] skills. Each attribute could take three possible ordinal values. There were $3 \times 3=27$ possible attribute combinations in each domain, all of which were presented in the first part of the study (270 choices) in random order. Then the first part of the study ended.

The second session of the study (the retest), took place approximately one week after the first session. The domain-specific multiple-attribute choice task was repeated once (270 choices), which allowed us to test the stability of choices. Participants further completed a standard numeric risky choice task in a description format between 99 risky and safe twooutcome lotteries in the gain, loss, and mixed domain. Nine of these lotteries were strongly dominated and used to screen out inattentive participants, and we used the remaining 89 lottery choices for the analyses. The lottery risky choice task was included to estimate prospect theory parameters.

The attributes, that we used for this choice task, were designed to be ecologically valid because they were based on the most-frequent attributes that people considered important to make choices in the ten risk domains (Jarecki \& Wilke, 2018). The vignettes were designed based on a pre-test to ensure that the vignettes did not lead to a ceiling or floor effect (i.e., only engagement or refraining). The behaviors in the choice task were formulated such that engaging in a behavior had a higher risk - in the sense of probabilistic costs and benefits relative to the status quo-whereas refraining from the behavior was safer - in the sense of a high probability to preserve the status quo. Attention-check questions ensured participants' awareness of the costs and benefits of engagement.

\footnotetext{
${ }^{2}$ Numeric slider from $0 \%-100 \%$.
} 
Table 1. Items in the multi-attribute domain-specific choice trials, designed based on previous research (see text)

\begin{tabular}{|c|c|c|c|c|c|}
\hline \multirow{2}{*}{\multicolumn{2}{|c|}{ Domain }} & \multirow[t]{2}{*}{ Choice Task Item } & \multicolumn{3}{|c|}{ Attributes } \\
\hline & & & Attribute $a_{l}$ & Attribute $a_{2}$ & Attribute $a_{3}$ \\
\hline $\mathrm{GC}$ & $\begin{array}{l}\text { Within-group } \\
\text { competition }\end{array}$ & Work weekends to be considered for a promotion & $\begin{array}{l}\text { This promotion is XXX } \\
\text { important to you. }\end{array}$ & $\begin{array}{l}\text { At work you possess } \\
\text { XXX skills. }\end{array}$ & $\begin{array}{l}\text { Your competitors pos- } \\
\text { sess XXX skills. }\end{array}$ \\
\hline BGC & $\begin{array}{l}\text { Between-group } \\
\text { competition }\end{array}$ & $\begin{array}{l}\text { Collectively downplay flaws in your team's project re- } \\
\text { port to outperform the competitor team. }\end{array}$ & $\begin{array}{l}\text { They usually consume } \\
\text { XXX food. }\end{array}$ & $\begin{array}{l}\text { They valued a recent } \\
\text { XXX dinner invitation. }\end{array}$ & $\begin{array}{l}\text { Their friends discuss } \\
\text { food quality in a XXX } \\
\text { manner. }\end{array}$ \\
\hline STA & $\begin{array}{l}\text { Status and } \\
\text { power }\end{array}$ & $\begin{array}{l}\text { Invite two colleagues from a new workplace for a rela- } \\
\text { tively expensive dinner to make an excellent impres- } \\
\text { sion. }\end{array}$ & $\begin{array}{l}\text { The temperature is } \\
\text { around XXX F. }\end{array}$ & $\begin{array}{l}\text { You will be joined by } \\
\text { XXX other people. }\end{array}$ & $\begin{array}{l}\text { The nature outdoors is } \\
\text { XXX beautiful. }\end{array}$ \\
\hline ENV & $\begin{array}{l}\text { Environmental } \\
\text { exploration }\end{array}$ & $\begin{array}{l}\text { Take a long walk to experience the landscape on an ex- } \\
\text { tremely hod day. }\end{array}$ & You are XXX hungry. & $\begin{array}{l}\text { The food has a XXX ap- } \\
\text { pearance. }\end{array}$ & $\begin{array}{l}\text { The counter is XXX } \\
\text { clean. }\end{array}$ \\
\hline FSE & Food & itting on the & $\begin{array}{l}\text { Costs for gardening } \\
\text { stress your budget } \\
\text { XXX. }\end{array}$ & stores co & $\begin{array}{l}\text { Eating home } \\
\text { has XXX hec }\end{array}$ \\
\hline FAC & $\begin{array}{l}\text { Food acquisi- } \\
\text { tion }\end{array}$ & $\begin{array}{l}\text { Engage in home-gardening to grow your own vegeta- } \\
\text { bles under varying weather conditions. }\end{array}$ & $\begin{array}{l}\text { You need the apartme } \\
\text { XXX. }\end{array}$ & $\begin{array}{l}\text { Paying stresses your par- } \\
\text { ents' budget XXX. }\end{array}$ & $\begin{array}{l}\text { Paying stresses your own } \\
\text { budget XXX. }\end{array}$ \\
\hline PAR & $\begin{array}{l}\text { Parental invest- } \\
\text { ment }\end{array}$ & $\begin{array}{l}\text { Ask your parents to help pay for the deposit on an apart- } \\
\text { ment. }\end{array}$ & $\begin{array}{l}\text { The estimated costs } \\
\text { equal XXX of your } \\
\text { savings. }\end{array}$ & $\begin{array}{l}\text { That this will help your } \\
\text { sibling is XXX sure. }\end{array}$ & $\begin{array}{l}\text { Your sibling and you are } \\
\text { XXX close. }\end{array}$ \\
\hline KIN & Kinship & $\begin{array}{l}\text { Pay one month's worth of your sibling's living costs so } \\
\text { that he/she can concentrate on an academic achievement } \\
\text { during this time. }\end{array}$ & $\begin{array}{l}\text { You currently have } \\
\text { XXX commitment in- } \\
\text { terest. }\end{array}$ & $\begin{array}{l}\text { Your dates have XXX } \\
\text { commitment interest. }\end{array}$ & $\begin{array}{l}\text { What you do will be } \\
\text { known to XXX of your } \\
\text { peers. }\end{array}$ \\
\hline MAT & Mate attraction & $\begin{array}{l}\text { Go on dates to expensive parts in town with different } \\
\text { people, to see if there is a match. }\end{array}$ & $\begin{array}{l}\text { Your partner has lately } \\
\text { been XXX caring for } \\
\text { you. }\end{array}$ & $\begin{array}{l}\text { You generally feel XXX } \\
\text { sure about the relation- } \\
\text { ship. }\end{array}$ & $\begin{array}{l}\text { Your partner would be } \\
\text { XXX upset by this. }\end{array}$ \\
\hline MRE & Mate retention & $\begin{array}{l}\text { Spend an evening with friends rather than on a date } \\
\text { night with your romantic partner. }\end{array}$ & $\begin{array}{l}\text { This promotion is } \mathrm{XXX} \\
\text { important to you. }\end{array}$ & $\begin{array}{l}\text { At work you possess } \\
\text { XXX skills. }\end{array}$ & $\begin{array}{l}\text { Your competitors pos- } \\
\text { sess XXX skills. }\end{array}$ \\
\hline
\end{tabular}

Note. Each attribute $a_{1}, a_{2}, a_{3}$ could take three possible values (substituting the XXX in the vignettes) a low, average, and high attribute value. Attribute value labels were worded to be appropriate for the domain-specific vignette, for example not very, moderately, very; or small, average, large. The attribute direction was chosen such that higher attribute values increased the risk for a negative consequence, independent of the label direction.

\section{Results}

We analyze the temporal stability of risky choices within domains, the ecological rationality of within-domain cost and benefit perceptions, and whether cost-benefit perceptions predict risky choices above the attributes in the domains.

\section{Reliability of domain-specific risky choice}

How reliable were the choices in the domains from the first part of the study to the retest? The retest presented the same vignettes approximately one week after the first session. Participants' risky choices were relatively stable within the domains (Figure 2), with an overall retest correlation of the proportion of risky choices by participant and domain of was $r=$ $0.725(S D=0.051)$, with significant domain-specific retestcorrelations $r_{\mathrm{BGC}}=0.78, r_{\mathrm{ENV}}=0.79, r_{\mathrm{FAC}}=0.72, r_{\mathrm{FSE}}=0.74$, $r_{\mathrm{KIN}}=0.80, r_{\mathrm{MAT}}=0.72, r_{\mathrm{MRE}}=0.63, r_{\mathrm{PAR}}=0.70, r_{\mathrm{STA}}=0.69$, $r_{\mathrm{WGC}}=0.68$, all $p \mathrm{~s}<.001$. A linear model ${ }^{3}$ comparison showed that adding the time of study (session one versus the

\footnotetext{
${ }^{3}$ Predicting the risky choice with a linear model with logit link and the predictors domain + gender + domain $x$ gender + benefit as
}

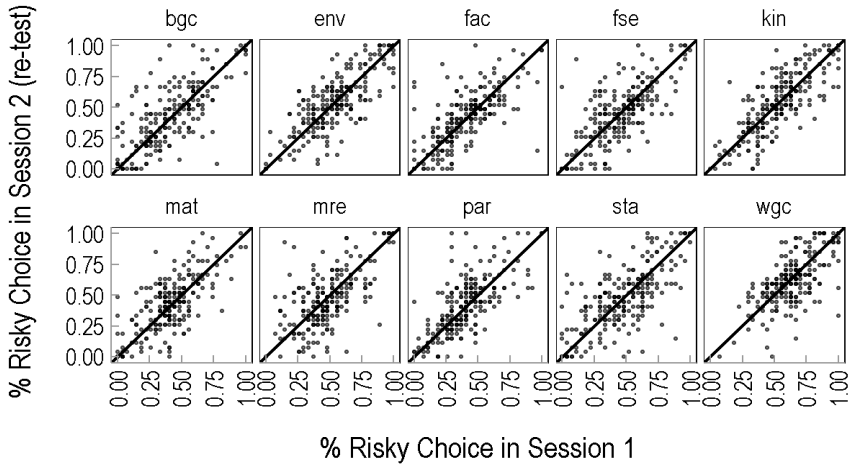

Figure 2. Reliability of risky choices in domains. Shown are participants' risky choice proportions in session 1 plotted against session 2 across the ten domains.

retest) as predictor did not significantly improve the model fit compared to the added model complexity, $\mathrm{AIC}_{+ \text {time }}=158,335$ $\sim \mathrm{AIC}_{\text {-time }}=158,334$ and $\mathrm{BIC}_{+ \text {time }}=158,559 \sim \mathrm{BIC}_{\text {-time }}=$ $158,547 \chi^{2}=0.143, p=0.705$. The increase in risk-taking

fixed effects and a by-participant random intercept. 
with the perceived benefit indicates that participants may have an intuitive notion of variance, which is in line with the widely held belief that, generally speaking, taking higher investment risks may lead to greater benefits (e.g., global data by the OECD, 2019).

\section{Predictors of domain-specific risky choice}

We analyzed the predictors of the observed choices in the ten domains of risk. We used a linear mixed model comparison, predicting the observed choices (logit link) as a function of the fixed-effect terms domain, gender, domain $\mathrm{x}$ gender, values of the $1^{\text {st }}, 2^{\text {nd }}$, and $3^{\text {rd }}$ attribute, session time (test/retest), and a by-participant random intercept. Table 2 shows the resulting comparison. The best-fitting model included domain, the domain $\mathrm{x}$ gender interaction, and the perception of benefits as predictors.

The best model also shows domaindifferences in the risk-taking propensities (post-hoc comparisons, see Table A1 in the Appendix), similar to previous findings (Wilke et al., 2014). The results show no significant overall gender difference $\left(\Delta b_{\mathrm{f}-\mathrm{m}}=0.055\right.$, $p=.478$ ), but differences in certain domains, which is contrary to the common notion that men are consistently more risk-taking than women (Byrnes et al., 1999). Women were more risk-taking than men in the mate retention domain $\left(\Delta b_{\mathrm{m}-\mathrm{w}}=-0.311, p\right.$ $<.001$ ), and men were more risk-taking than women in the food acquisition $\left(\Delta b_{\mathrm{m}-\mathrm{w}}=0.287, p<0.001\right)$, status $\left(\Delta b_{\mathrm{m}-\mathrm{w}}=0.228, p=0.007\right)$ and mate attraction domain $\left(\Delta b_{\mathrm{m}-\mathrm{w}}=0.205, p=\right.$ .016)

The results of the best-fittin gmodel are in line with the risk-return view on risk-taking (Weber \& Milliman, 1997) in the sense that participants' perceptions of the benefits associated with the risky behavior increased their propensity for risk-taking, $b=$ $0.13, p<.001$ (model 1, Table 2). Including the attribute values of the cignettes as predictor did not significantly improve the model fit compared to the added model complexity, $\mathrm{AIC}_{\text {-att }}=158,338 \sim \mathrm{AIC}_{\text {+att }}=158,334$ and $\mathrm{BIC}_{\text {-att }}=158,547<\mathrm{BIC}_{\text {+att }}=$ $158,581, \chi^{2}=1.72, p=.634$.

\section{Random Effects} sidual variance,

$\sigma^{2}$ variance, $\tau_{00}$
The influences of the benefit perceptions on risky choices are stronger than the influence of situation-specific attributes: The comparison also reveals a significant effect of the benefit perceptions on risk-taking $(b=0.14, p<.001)$ over and above the influence of the attribute values, AIC(benefit) $=179,510$, AIC(attributes) $=180,583, \chi^{2}=0.801$. The best-fitting model included the perceived benefits $(b=0.14, p<.001)$.. This

Table 2. Predictors of the "Engage" (Risky) Choices in the Domain-Specific Choice Task

\begin{tabular}{|c|c|c|c|c|c|c|c|c|}
\hline \multirow[b]{2}{*}{ Fixed Effects } & \multicolumn{8}{|c|}{ Coefficients (unstandardized) } \\
\hline & (1) & (2) & (3) & (4) & (5) & (6) & (7) & (8) \\
\hline (Intercept) & $-0.74^{* * *}$ & $-0.74^{* * *}$ & $-0.76^{* * *}$ & $-0.76^{* * *}$ & $0.31^{* * *}$ & $0.29^{* * *}$ & $-0.14^{* *}$ & $-0.12^{* *}$ \\
\hline Gender: Male & 0.03 & 0.03 & 0.03 & 0.03 & 0.00 & 0.00 & 0.01 & 0.01 \\
\hline BGC & $-0.32^{* * *}$ & $-0.32^{* * *}$ & $-0.32^{* * *}$ & $-0.33^{* * *}$ & $-0.31^{* * *}$ & $-0.31^{* * *}$ & $-0.36^{* * *}$ & $-0.36^{* * *}$ \\
\hline WGC & $0.57^{* * *}$ & $0.57^{* * *}$ & $0.57^{* * *}$ & $0.57^{* * *}$ & $0.69^{* * *}$ & $0.69^{* * *}$ & $0.73^{* * *}$ & $0.73^{* * *}$ \\
\hline STA & $0.04^{*}$ & $0.04^{*}$ & $0.04^{*}$ & $0.05^{* *}$ & -0.02 & -0.02 & -0.01 & 0.00 \\
\hline ENV & $0.32^{* * *}$ & $0.32^{* * *}$ & $0.32^{* * *}$ & $0.32^{* * *}$ & $0.33^{* * *}$ & $0.33^{* * *}$ & $0.31^{* * *}$ & $0.31^{* * *}$ \\
\hline FSE & $-0.11^{* * *}$ & $-0.11^{* * *}$ & $-0.11^{* * *}$ & $-0.11^{* * *}$ & $-0.19^{* * *}$ & $-0.19^{* * *}$ & $-0.09^{* * *}$ & $-0.11^{* * *}$ \\
\hline FAC & $-0.17^{* * *}$ & $-0.17^{* * *}$ & $-0.17^{* * *}$ & $-0.14^{* * *}$ & $-0.30^{* * *}$ & $-0.30^{* * *}$ & $-0.35^{* * *}$ & $-0.32^{* * *}$ \\
\hline PAR & $-0.42^{* * *}$ & $-0.42^{* * *}$ & $-0.42^{* * *}$ & $-0.43^{* * *}$ & $-0.35^{* * *}$ & $-0.35^{* * *}$ & $-0.29^{* * *}$ & $-0.29^{* * *}$ \\
\hline KIN & $0.32^{* * *}$ & $0.32^{* * *}$ & $0.32^{* * *}$ & $0.32^{* * *}$ & $0.32^{* * *}$ & $0.32^{* * *}$ & $0.29^{* * *}$ & $0.28^{* * *}$ \\
\hline MAT & $-0.25^{* * *}$ & $-0.25^{* * *}$ & $-0.25^{* * *}$ & $-0.24^{* * *}$ & $-0.22^{* * *}$ & $-0.22^{* * *}$ & $-0.27^{* * *}$ & $-0.25^{* * *}$ \\
\hline Male x BGC & -0.03 & -0.03 & -0.03 & & 0.01 & 0.01 & -0.01 & \\
\hline Male x WGC & 0.02 & 0.02 & 0.02 & & $0.04^{*}$ & $0.04^{*}$ & 0.03 & \\
\hline Male x STA & $0.09^{* * *}$ & $0.09^{* * *}$ & $0.09^{* * *}$ & & $0.07^{* * *}$ & $0.07^{* * *}$ & $0.07^{* * *}$ & \\
\hline Male x ENV & 0.01 & 0.01 & 0.01 & & 0.02 & 0.02 & 0.03 & \\
\hline Male x FSE & $-0.06^{* *}$ & $-0.06^{* *}$ & $-0.06^{* *}$ & & $-0.13^{* * *}$ & $-0.13^{* * *}$ & $-0.12^{* * *}$ & \\
\hline Male x FAC & $0.12^{* * *}$ & $0.12^{* * *}$ & $0.12^{* * *}$ & & $0.13^{* * *}$ & $0.13^{* * *}$ & $0.13^{* * *}$ & \\
\hline Male x PAR & -0.01 & -0.01 & -0.01 & & -0.03 & -0.03 & -0.02 & \\
\hline Male x KIN & -0.03 & -0.03 & -0.03 & & $-0.05^{* *}$ & $-0.05^{* *}$ & -0.03 & \\
\hline Male x MAT & $0.08^{* * *}$ & $0.08^{* * *}$ & $0.08^{* * *}$ & & $0.11^{* * *}$ & $0.11^{* * *}$ & $0.12^{* * *}$ & \\
\hline Time (re-test) & & 0.00 & & 0.00 & & & & 0.00 \\
\hline Benefit & $0.13^{* * *}$ & $0.13^{* * *}$ & $0.13^{* * *}$ & $0.13^{* * *}$ & & & & \\
\hline Cost & & & & & $-0.10^{* * *}$ & $-0.10^{* * *}$ & & \\
\hline Attribute 1 & & & 0.00 & & & 0.00 & 0.00 & \\
\hline Attribute 2 & & & 0.00 & & & 0.00 & 0.00 & \\
\hline Attribute 3 & & & 0.01 & & & 0.01 & 0.01 & \\
\hline
\end{tabular}

Within-group re-

Between-group $\quad 0.32$ id

\begin{tabular}{lllllllll} 
ICC & \multicolumn{1}{c}{0.09} \\
\hline$N$ & & \multicolumn{7}{c}{226} \\
AIC & 158,334 & 158,335 & 158,338 & 158,496 & 158,653 & 158,657 & 159,181 & 159,426 \\
\hline
\end{tabular}

Note. $* p<.05 * * p<.01 * * * p<.001$

$\mathrm{BGC}=$ between-group competition, $\mathrm{WGC}=$ within-group competition, $\mathrm{STA}=$ status and power, $\mathrm{ENV}=$ environmental exploration, $\mathrm{FSE}=$ food selection, $\mathrm{FAC}=$ food acquisition, $\mathrm{KIN}=$ kinship, MAT = mate attraction; baseline $=$ mate retention; $\mathrm{ICC}=$ intraclass correlation coefficient; $\mathrm{AIC}=$ Akaike Information Criterion . 
This suggests that for that people process risks by the consequences of their choices rather than by a focus on the features of the choice situation. Regarding this result it is worth highlighting that, the benefits of the risky situations were reinforced during the choice task, rather did the choice task only present the attributes of the situations to participants (Figure 1). Therefore, it is somewhat surprising that the attribute values of the situations did not explain the risky choices better than the benefit perceptions.

Robustness against the exclusion of participants. The descriptive data showed that some participants took several hours to complete the first session of the survey; also, others failed attention checks in the risky lottery task, defined as selecting multiple dominated gambles (e.g., 25 with $20 \%$ or 75 versus -5 with $70 \%$ or 20 ). Thus, we re-analyzed the data fitting the models to a subset of the data after excluding $n=15$ participants whose a log completion time fell outside of Med $+/-3 \times I Q R$ and excluding $n=26$ who chose more than four of nine dominated lotteries. The overall results that we found with the full data (Table 2) were robust. Therefore, we conducted the remaining analyses with the full sample.

\section{Exploring the ecological rationality of beliefs and choice in domains}

For each of the behaviors in the ten risk domains under study (Table 1), we obtained an approximation of the monthly median real financial costs and benefits and the associated relative frequencies from statistical databases in the United States (using e.g., the Center for Disease Control and Prevention Statistics, National Center for Health Statistics United States Bureau of Labor Statistics). For example, in the within-group competition domain the benefit in terms of the median pay rise given upon promotion equaled $\$ 400$ (U.S. Bureau of Labour Statistics, 2018; World at Work, 2018), and in the parental investment domain, the benefit in terms of the median amount of rent in the area of the study equaled $\$ 1,170$. We were able to approximate the monetary costs and probabilities for behaviors, but no for the behavior given different attribute values, and we acknowledge that the aggregate values are a crude approximation of the average costs and benefits. Therefore we only use the rank-order of the approximate costs, rather than the mean costs, in the analyses. To assess if people's perceptions about the risks and benefits across domains were approximately accurate, we correlated the perceived net benefit (benefit rating - cost rating) with the true rank of the net benefit. The results show that participants' actual choice proportion across the domains correlated with the real expected value rank of the costs of the domains (Spearman's rho $=0.166, p<.001$ ). Also, participants' perceived net benefit was correlated with the approximated real net benefits (Kendall's $t a u=0.045, p=.004$ ). However, the estimates of the probabilities of benefits and costs were not significantly correlated with the true figures $\left(r_{\mathrm{p}(\text { benefit }}\right)=$ $0.029, p=0.165$ and $\left.r_{\mathrm{p}(\mathrm{cost})}=-0.036, p=.084\right)$.

\section{The role of Prospect Theory in contextualized risky choice}

Do the risk preference parameters obtained from cumulative prospect theory in a standard risky choice task - in which participants decide about lotteries - explain inter-individual differences in risk-taking across domains? We used the data collected during the second session of the study, in which participants made binary choices between 89 pairs of numerically described risky lotteries, and estimated the parameters of cumulative prospect theory (Tversky \& Kahneman, 1992) via maximum likelihood. We used a three-parameter version of prospect theory with the following parameters: $\alpha$ measuring the curvature of the utility of outcomes (risk aversion), $\gamma$ measuring probability distortion, and $\lambda$ measuring the weighting of losses relative to gains and $\tau$ for choice-sensitivity (Broomell \& Bhatia, 2014); parameters were estimated at the individual level. The resulting mean $(S D)$ parameter values were comparable to the parameter values obtained in prior work (e.g., Tversky \& Kahneman, 1992).

To test if the prospect theory parameters explain inter-individual differences in domain-specific risk-taking, we correlated them with the data from the risky choice task (mean "engage" choice proportion from both study parts). Table 3 shows the correlations of the parameters from prospect theory with the percentage of "engage" (risky) choices in our domain-specific risky choice task. The observed risky decisions in the domains were not substantially related to any of prospect theory's parameters (parameter inter-correlations are typical for this model; Krefeld-Schwalb et al., 2019). One explanation for this is that the numerical financial domain and other domains of risk-taking are treated differently by people (e.g., Breuer et al., 2013).

Table 3. Correlation of the "Engage" (Risky) Choices $p_{\text {risk }}$ in the Domain-specific Choice Task with Cumulative Prospect

Theory Parameters in a Standard Risky Lottery Task

\begin{tabular}{lccc}
\hline & $\begin{array}{c}\text { Risky } \\
\text { choice } \\
p_{\text {risk }}\end{array}$ & $\begin{array}{c}\text { Risk aver- } \\
\text { sion }\end{array}$ & $\begin{array}{c}\text { Probability } \\
\text { weight }\end{array}$ \\
\hline$p_{\text {risky }}$ & - & $\alpha$ & $\gamma$ \\
$\alpha$ & -.10 & - & - \\
$\gamma$ & .06 & $22^{* *}$ & - \\
$\lambda$ & .02 & $-.40^{* * *}$ & - \\
\hline Note. $^{*} p<.05 ; * * p<.01 ; * * *$ & 0.001 &
\end{tabular}

\section{Discussion}

We investigated the stability of risky choices in ten domains of life and tested if risky choices in different domains of life can be accounted for by the risk-return framework, which assumes that a trade-off between the perceived cost and benefit governs risk propensities, or by the situational attributes in the context. Lastly, we tested if prospect theory can account for inter-individual differences in risk-taking in real-life do- 
mains. We employed a novel contextualized multiple-attribute risk-taking task, which uses the most-important aspects in different domains of risk as stimulus attributes.

Regarding the stability of risk-taking, our results show that risk-taking is very stable within domains across time. Regarding the role of cost and benefit perceptions in risk taking, the results show that in line with a risk-return framework (e.g., Weber, 1999), cost and benefit perceptions have a stronger influence on risk taking than linear combinations of the values of the situational attributes, which speaks to a weighting and adding strategy of risk taking. Interestingly, we found that both, cost and benefit perceptions, increased the propensity to take risks, which speaks against a trade-off between cost and benefit perceptions in risk-taking, but rather for that people are aware that risky options with high returns, which are worth taking, often come with a high benefit and a high cost (risk premium, e.g., Dimson et al., 2003).

To test if the risky choices across real-life domains can be explained by standard experimental measures of risk attitudes, we estimated cumulative prospect theory's risk attitude parameter in a traditional risky choice task. The results show that individual prospect theory parameters do not explain risk-taking in a contextualized choice task.

Taken together, this work shows a novel experimental paradigm to study risks in real-life situations, which produces stable behavioral choices. This paradigm further provides opportunities for cognitive scientists to investigate the information integration processes that govern risky decision making in contexts of real-life domains, which we believe is an important avenue in the future of risk propensity research.

\section{References}

Blais, A.-R., \& Weber, E. U. (2006). A domain-specific risktaking (DOSPERT) scale for adult populations. Judgment and Decision Making, 1, 33-47.

Breuer, W., Kollath, J., Salzmann, A. J., \& von Nitzsch, R. (2013). The Assessment of Risk Behavior: A CrossCultural Analysis Using the DOSPERT Scale. Ssrn, February 2018. https://doi.org/10.2139/ssrn.2292364

Broomell, S. B., \& Bhatia, S. (2014). Parameter recovery for decision modeling using choice data. Decision, 1(4), 252-274. https://doi.org/10.1037/dec0000020

Byrnes, J. P., Miller, D. C., \& Schafer, W. D. (1999). Gender differences in risk taking: A meta-analysis. Psychological Bulletin, 125(3), 367-383. https://doi.org/10.1037/0033-2909.125.3.367

Dimson, E., Marsh, P., \& Staunton, M. (2003). Global Evidence on the equity risk premium. Journal of Applied Corporate Finance, 15(4), 27-38. https://doi.org/10.2139/ssrn.431901

Frey, R., Pedroni, A., Mata, R., Rieskamp, J., \& Hertwig, R. (2017). Risk preference shares the psychometric structure of major psychological traits. Science Advances, 1-14. https://doi.org/10.1126/sciadv.1701381

Jarecki, J. B., \& Wilke, A. (2018). Into the black box: Tracing information about risks related to 10 evolutionary problems. Evolutionary Behavioral Sciences, 12(3), 230-244. https://doi.org/10.1037/ebs0000123

Johnson, J. G., Wilke, A., \& Weber, E. U. (2004). Beyond a trait view of risk taking: A domain-specific scale measuring risk perceptions, expected benefits, and perceived-risk attitudes in German-speaking populations. Polish Psychological Bulletin, 35, 153163.

Kahneman, D., \& Tversky, A. (1979). Prospect theory: An analysis of decision under risk. Econometrica, 47(3), 263-291. https://doi.org/10.2307/1914185

Krefeld-Schwalb, A., Pachur, T., \& Scheibehenne, B. (2019). Structural Parameter Interdependencies in Cognitive Models. https://doi.org/10.31234/osf.io/pxmnw

Nicholson, N., Soane, E., Fenton-O’Creevy, M., \& Willman, P. (2005). Personality and domain-specific risk taking. Journal of Risk Research, 8(2), 157-176. https://doi.org/10.1080/1366987032000123856

Nosić, A., \& Weber, M. (2010). How riskily do I invest? The role of risk attitudes, risk perceptions, and overconfidence. Decision Analysis, 7(3), 282-301. https://doi.org/10.1287/deca.1100.0178

OECD. (2019). OECD Financial education and consumer protection. http://www.oecd.org/finance/financialeducation/

Pleskac, T. J., \& Hertwig, R. (2014). Ecologically rational choice and the structure of the environment. Journal of Experimental Psychology: General, 143(5), 20002019. https://doi.org/10.1037/h0042769

Tversky, A., \& Kahneman, D. (1992). Advances in prospect theory: Cumulative representation of uncertainty. Journal of Risk and Uncertainty, 5(4), 297-323. https://doi.org/10.1007/BF00122574

U.S. Bureau of Labour Statistics. (2018). BLS Household data 2017: Median weekly earnings of full-time wage and salary workers by detailed occupation and sex. https://www.bls.gov/cps/cpsaat39.htm

Weber, E. U. (1999). Who's afraid of a little risk? New evidence for general risk aversion. Decision Research from Bayesian Approaches to Normative Systems, 1953, 53-64.

Weber, E. U., \& Milliman, R. A. (1997). Perceived risk attitudes: Relating risk perception to risky choice. Management Science, 43(2), 123-144. https://doi.org/10.1287/mnsc.43.2.123

Wilke, A., Sherman, A., Curdt, B., Mondal, S., Fitzgerald, C., \& Kruger, D. J. (2014). An Evolutionary DomainSpecific Risk Scale. Evolutionary Behavioral Sciences, 8(3), 123-141. https://doi.org/10.1037/ebs0000011

World at Work. (2018). WorldatWork 2017-2018 Salary Budget Survey. https://www.worldatwork.org/resources/surveys/salar $\mathrm{y}$-and-budget-survey-worldatwork-surveys

\section{Appendix}


Table A1 shows the post-hoc tests for the pairwise comparisons between risk-taking in the domains by gender and the respective p-values (upper triangles)

Table A1. Post-hoc Tests - Pairwise Comparisons

\begin{tabular}{|c|c|c|c|c|c|c|c|c|c|c|c|c|c|c|c|c|c|c|c|c|}
\hline & \multicolumn{10}{|c|}{ Female } & \multicolumn{10}{|c|}{ Male } \\
\hline & BGC & ENV & FAC & FSE & KIN & MAT & MRE & PAR & STA & WGC & BGC & ENV & FAC & FSE & KIN & MAT & MRE & PAR & STA & WGC \\
\hline BGC & & $<.0001$ & $<.0001$ & $<.0001$ & $<.0001$ & $<.0001$ & 0.4586 & $<.0001$ & $<.0001$ & $<.0001$ & & $<.0001$ & $<.0001$ & $<.0001$ & $<.0001$ & 1.0000 & 0.1066 & $<.0001$ & 0.9974 & $<.0001$ \\
\hline ENV & -0.953 & & $<.0001$ & $<.0001$ & $<.0001$ & $<.0001$ & $<.0001$ & $<.0001$ & $<.0001$ & $<.0001$ & $-8 \mathrm{e}-01$ & & $<.0001$ & $<.0001$ & $<.0001$ & $<.0001$ & $<.0001$ & 0.0002 & $<.0001$ & $<.0001$ \\
\hline FAC & -0.479 & 0.474 & & $<.0001$ & $<.0001$ & $<.0001$ & $<.0001$ & $<.0001$ & $<.0001$ & $<.0001$ & $-2 \mathrm{e}-01$ & $6 e-01$ & & $<.0001$ & 1.0000 & $<.0001$ & $<.0001$ & $<.0001$ & $<.0001$ & $<.0001$ \\
\hline FSE & -0.689 & 0.264 & -0.209 & & $<.0001$ & $<.0001$ & $<.0001$ & 0.9787 & $<.0001$ & $<.0001$ & $-6 e-01$ & $2 \mathrm{e}-01$ & $-4 \mathrm{e}-01$ & & $<.0001$ & $<.0001$ & $<.0001$ & 0.9632 & $<.0001$ & 0.2414 \\
\hline KIN & -0.194 & 0.759 & 0.285 & 0.494 & & 0.0493 & $<.0001$ & $<.0001$ & 1.0000 & 1.0000 & $-2 \mathrm{e}-01$ & $6 e-01$ & $-8 \mathrm{e}-04$ & $4 \mathrm{e}-01$ & & $<.0001$ & $<.0001$ & $<.0001$ & $<.0001$ & $<.0001$ \\
\hline MAT & -0.307 & 0.646 & 0.173 & 0.382 & -0.112 & & $<.0001$ & $<.0001$ & 0.0126 & 0.0426 & $-9 \mathrm{e}-03$ & $8 \mathrm{e}-01$ & $2 \mathrm{e}-01$ & $6 e-01$ & $2 \mathrm{e}-01$ & & 0.0749 & $<.0001$ & 0.9871 & $<.0001$ \\
\hline MRE & 0.078 & 1.032 & 0.558 & 0.767 & 0.273 & 0.385 & & $<.0001$ & $<.0001$ & $<.0001$ & $1 \mathrm{e}-01$ & $1 \mathrm{e}+00$ & $4 \mathrm{e}-01$ & $7 \mathrm{e}-01$ & $4 \mathrm{e}-01$ & $1 \mathrm{e}-01$ & & $<.0001$ & 0.5750 & $<.0001$ \\
\hline PAR & -0.648 & 0.305 & -0.169 & 0.040 & -0.454 & -0.342 & -0.727 & & $<.0001$ & $<.0001$ & $-6 e-01$ & $2 \mathrm{e}-01$ & $-4 e-01$ & $-5 e-02$ & $-4 \mathrm{e}-01$ & $-6 e-01$ & $-8 \mathrm{e}-01$ & & $<.0001$ & 0.0056 \\
\hline STA & -0.179 & 0.774 & 0.300 & 0.510 & 0.016 & 0.128 & -0.257 & 0.469 & & 1.0000 & $4 e-02$ & $9 \mathrm{e}-01$ & $3 e-01$ & $6 e-01$ & $3 e-01$ & $5 e-02$ & $-9 \mathrm{e}-02$ & $7 \mathrm{e}-01$ & & $<.0001$ \\
\hline WGC & -0.192 & 0.761 & 0.287 & 0.496 & 0.002 & 0.114 & -0.271 & 0.456 & -0.014 & & $-5 e-01$ & $3 e-01$ & $-3 e-01$ & $1 \mathrm{e}-01$ & $-3 e-01$ & $-5 e-01$ & $-6 e-01$ & $2 \mathrm{e}-01$ & $-5 e-01$ & \\
\hline
\end{tabular}

Note. The upper tringles that are shaded in grey show p-values (Tuckey adjusted), lower triangles show the pairwise comparison of the estimated effects of domains on risk taking given gender obtained from the best-fitting linear model (see main text and Table 2). 